\title{
Product Recovery-Cycles Design
} Extension of Useful Life

\author{
F. GIUDICE, G. LA ROSA and A. RISITANO
}

DIIM Department of Industrial and Mechanical Engineering, University of Catania, Viale A. Doria 6, 95125 Catania, Italy - e-mail: fgiudice@diim.unict.it

\begin{abstract}
This paper reports the development of a tool to aid designers in making the best choices in order to plan recovery cycles for a product at the end of its working life. Having outlined an effective design methodology for this purpose, a calculation model was developed to support the methodology. The model was based on the quantification of determining factors, allowing the definition of the reusable parts of the architecture and the evaluation of the values assumed by an indicator which translates the environmental effects of recovery cycles in terms of extension of the product's useful life. A trial conducted on a commonly used industrial unit, a heat exchanger, demonstrated the value of the design tool in comparing different architectures of a product and their optimisation, confirming its effectiveness as calculation model for the environmental quality-oriented product design.
\end{abstract}

Key words: Life-Cycle Design, Design for Environment, Recovery Cycles, Intensity of Use, Useful Life

\section{INTRODUCTION}

The continuous search for ever greater competitive advantage in industry has led to the development of products which offer not only high quality standards throughout their working life, but also a wide range of properties characterising their performance in different phases of their whole life cycle.

These production requirements have influenced the evolution of design methodologies which reflect how initial design choices can greatly affect a product's performance over its entire life cycle, in terms of functionality, ease of production and servicing, and environmental impact (Kusiak 1992, Ishii 1995, Huang 1996).

The original version of this chapter was revised: The copyright line was incorrect. This has been corrected. The Erratum to this chapter is available at DOI: 10.1007/978-0-387-35637-2_11 
In the context of these new methodological approaches, known as LifeCycle Design or Design for X (DFX), Design for Environment (NavinChandra 1991, Billatos 1997, Graedel 1998) is directed at providing products with an elevated level of eco-compatibility over their entire life cycle. Its principle objective, that is to optimise the distribution of the flows of resources over the product's whole life cycle, can be followed by many strategies. Of particular importance are those concerning the recovery of components and materials at the end of the product's working life (disassembly, selection, inspection, direct reuse of components, recycling material in primary or external production cycles), in that they are directed at closing the resource flow cycles through recycling (Figure 1).

These strategies translate into design approaches which target disassembly, recovery and recycling, known as Design for Disassembly and Recycling (Burke 1992, Dowie 1995, Ishii 1999).

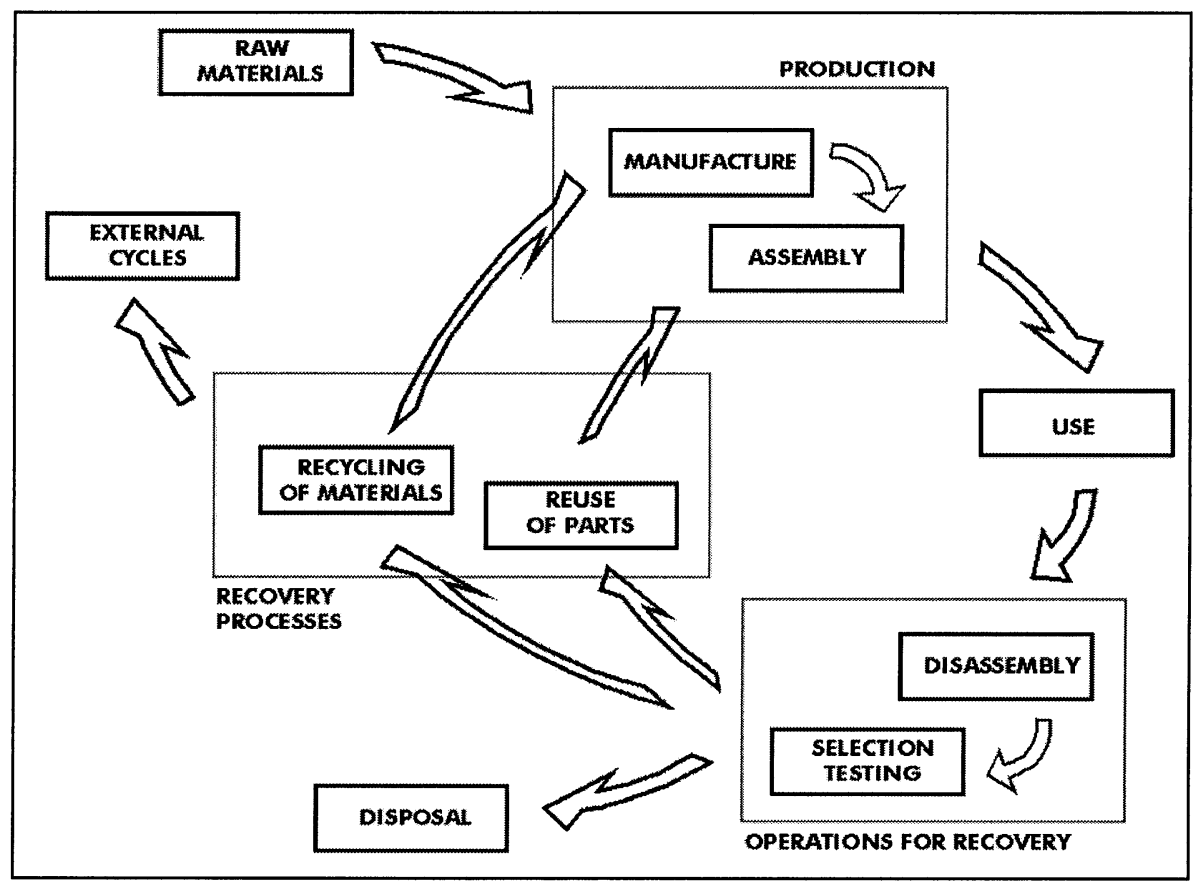

Figure 1. Life cycle and resources recovery strategies 


\section{DEFINITION OF THE PROBLEM AND AIMS}

Recovery operations at the end of a product's life can be divided into the following main phases (Figure 1):

- disassembly of parts;

- selection and inspection of their condition;

- direct reuse of complete components;

- recycling materials in the primary production cycle or in external cycles. Thus the suitability and effectiveness of these operations are strictly dependent on several determining factors which characterise the architecture of the constructional unit:

- the detachability of components (depending on the layout of the unit and on the geometry and the junctions between parts);

- the property of component durability, which conditions the process of declining performance over time, and consequently determines their suitability for reuse;

- the appropriateness and suitability of recycling material from parts are not reusable.

On the basis of the experience of manufacturers operating in the industrial plant sector, for some product typologies, it seems that generally resources are used at a low intensity in that some parts of a constructional unit were still efficient at the end of its conventional life span and, therefore, potentially could guarantee further durability, but were nevertheless thrown out with the entire product. This evidenced interesting margins in which operations of component reuse could be applied. In the light of these considerations, the research was orientated towards the development of a tool able to translate some determining design choices into opportunities for component recovery by means of a mathematical model which simulates possible recovery cycles at the end of the product's working life and quantifies the benefit in environmental terms.

The aim, therefore, was to develop a design tool which allows architectures to be compared and optimised, in terms of component separability and the distribution of their useful life in the unit, for an effective recycling of resources.

\section{DESIGN METHODOLOGY}

The problem under examination and the stated objective suggested the development of a design methodology which can be schematised as in Figure 2. 
The first phase, defining the overall architecture of the product using conventional design tools, consists of identifying the principle components of the system, their spatial and functional arrangement, jointing systems, and the overall geometry and materials of each component.

This is followed by a phase in which the conventional architecture so defined was analysed in relation to the recovery strategies. This analysis seeks to interpret the architecture in terms of component modules, highlighting the property of durability of performance in time and the jointing restraints (reversible/irreversible) which condition the possibility of separating a component from the rest of the unit. With regard to this last point, a qualitative analysis based on simple observation of the system's architecture can be complemented by an analytical approach to the problem of evaluating the separability of each component, or module, using appropriate models for the analysis of disassembly plans. This allows the design method to be further broken down, integrating it with the tools of Design and Planning for Disassembly, which are directed at optimising the disassembly procedure by reducing the associated costs, operating on the modularity and the choice of jointing systems in the unit (Navin-Chandra 1994, Lambert 1997, Johnson 1998, Tang 2000).

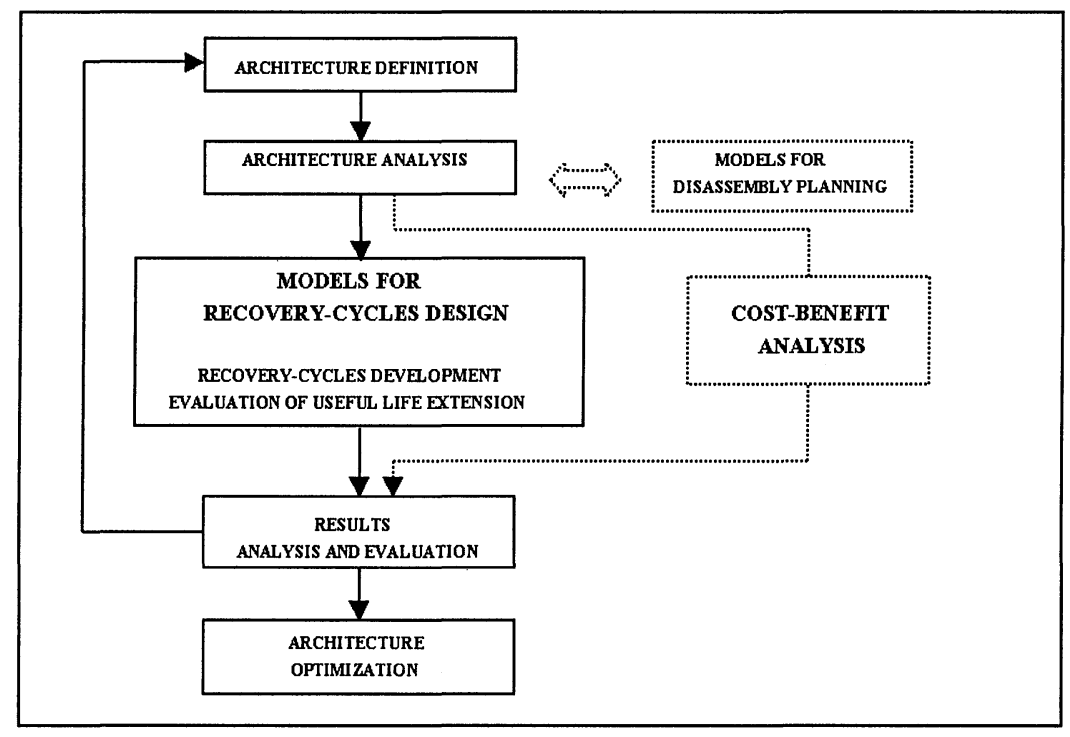

Figure 2. Design methodology

The data obtained in the architecture analysis is then elaborated using the calculation model proposed here which develops and analyses the possible recovery cycles, and evaluates their environmental effectiveness by means of 
an indicator which quantifies the intensity of resource use in terms of extension of the product's useful life. This approach, which allow the optimisation of the product's environmental performance, could be complemented by an analysis which evaluates the not insignificant life-cycle costs related to the recovery strategies. The analytical formulation of the problem allows the developed tool to be integrated with others for the costbenefit analysis of recovery processes (see Figure 2), such as those already proposed by the authors (Giudice 1999a). This specific problem will be subject of further works.

The final phase consists of evaluating the results obtained with applied calculation models, which can provide suggestions for a correct redesign of the architecture to obtain a definition which manages to harmonise the requirements of conventional design (functionality, safety, costs) with environmental demands.

\section{CALCUlation MODEL}

The calculation model proposed here, developed as an aid to the design of product recovery cycles, has the function of analysing the architecture data, translating this into the suitability of a component for reuse, and calculating the outcome of the possible recovery cycles at the end of the product's ordinary working life, quantifying the advantages in terms of value of resources used in production, and consequent environmental protection.

\subsection{Basic procedure of the calculation model}

The calculation model, represented in the design methodology (Figure 2), is based on a procedure summarised in Figure 3.

The data supplied by the analysis of the architecture is initially elaborated to identify the determining factors for component recovery, i.e. the property of each component which determines the possibility and suitability of its recovery and reuse. As we have seen, these factors were identified as the predicted duration of functional efficiency and safety of each component, and as its separability from the rest of the unit. It is then possible to evaluate the reusability of the components, i.e. the possibility of reusing them one or more times, and consequently to plan all the possible recovery cycles. The final phase of the calculation procedure translates the recovery plans into intensity of use of the resources, introducing an indicator of extension of the product's useful life. 


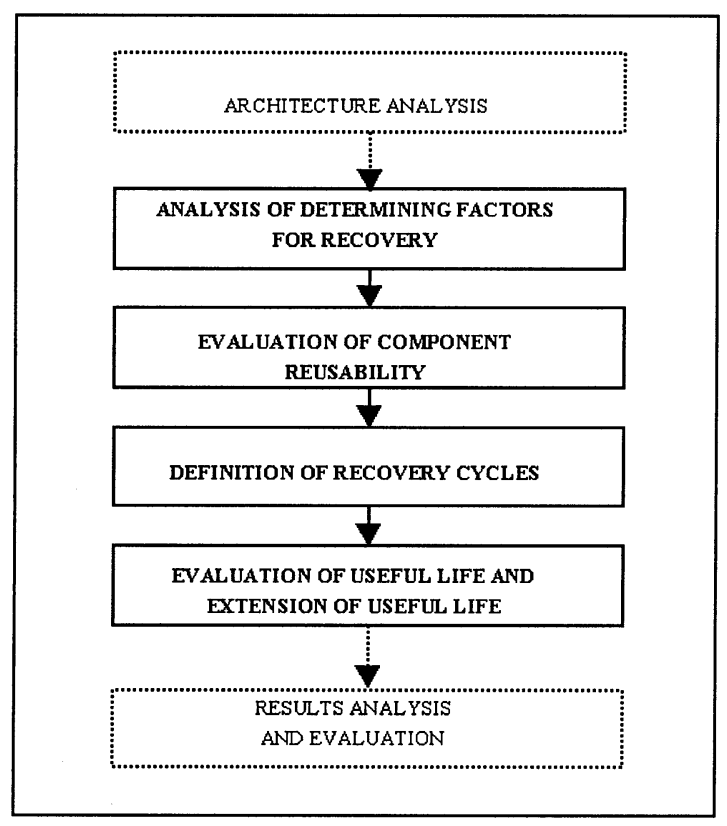

Figure 3. Basic procedure of calculation model

\subsection{Determining factors for recovery}

The analysis of the overall architecture, conceived according conventional design criteria, allows the identification of $\mathrm{n}$ principle components $\mathrm{C}_{\mathrm{i}}$ making up the unit, each characterised by weight $\mathrm{P}_{\mathrm{i}}$ and material $\mathrm{M}_{\mathrm{i}}$. Having identified the components, which may be grouped in construction modules, two factors determining their suitability for recovery and reuse must be defined: durability and separability.

The durability $D_{i}$ of the i-th component is the ratio between the predictable duration of component $\mathrm{DP}_{\mathrm{i}}$, and the duration of the product's conventional working life $\mathrm{T}$ :

$$
D_{i}=\operatorname{int}\left(\frac{D P_{i}}{T}\right)
$$

The terms $\mathrm{DP}_{\mathrm{i}}$ depend on design choices, and are quantifiable on the basis of modern design methods, which make it possible to guarantee the complete efficiency of the component in time, and on the basis of information obtained from the past behaviour of pre-existing components. The duration $\mathrm{T}$ is the time predicted for the normal use of the entire product without the substitution of any part. 
The separability of the i-th component expresses the possibility of disassembling and separating the component from the unit in order to recover it. This depends not only on the lay-out of the architecture and on the jointing constraints, but also on the relation between the component in question and other components characterised by the same durability, because, in recovery terms, a component is separable if it can be disassembled from the unit, or if it belongs to a group of components characterised by the same durability, and therefore constituting a single recoverable sub-unit, which can be disassembled.

To better define the separability, from (1) it is possible to find the number of potential reuses $\mathrm{R}_{\mathrm{i}}$ of each $\mathrm{i}$-th component on the basis of its durability:

$$
R_{i}^{*}=D_{i}-1
$$

Consequently, the $\mathrm{i}$-th component potentially takes part in the $\mathrm{j}$-th recovery cycle if the condition $R_{i} \geq j$ is true. From the verification of conditions of this type it is possible to identify the group of components which, for durability, could be included in each potential recovery cycle.

The separability $S_{i j}$ of the $i$-th component at the $j$-th recovery cycle is thus defined as follows: $S_{\mathrm{ij}}$ assumes a value 1 if it is possible to disassemble the single $\mathrm{i}$-th component or the group of components potentially reusable at the $\mathrm{j}$-th recovery cycle to which the $\mathrm{i}$-th component belongs, otherwise it is equal to 0 .

\subsection{Determining factors matrices and recovery vectors}

Indicating by $\mathrm{m}^{*}$ the overall number of potential recovery cycles $\left(\mathrm{m}^{*}=\right.$ $\max \left(\mathrm{R}_{\mathrm{i}} \mathrm{i}\right)$ ), it is then possible to define the $\mathrm{m}^{*}$ matrices of the determining factors for each $\mathrm{j}$-th recovery $\mathrm{M}^{\mathrm{FR}}$, which collects the durability and separability factors of all the components:

$$
M_{j}^{F R}=\left[\begin{array}{ll}
D_{i} & S_{i j}
\end{array}\right]_{i=1,2, \ldots, n}
$$

and the corresponding recovery vectors $\mathrm{V}_{\mathrm{j}}^{\mathrm{R}}$

$$
V_{j}^{R}=\left[V_{i j}^{R}\right]_{i=1,2, \ldots, n}
$$

which collect the $n$ terms $\mathrm{V}^{\mathrm{R}}{ }_{\mathrm{ij}}$ defined thus: 


$$
V_{i j}^{R}=D_{i} \cdot S_{i j}
$$

For the $\mathrm{i}$-th component to be effectively reusable at the $\mathrm{j}$-th recovery cycle, the condition $\mathrm{V}^{\mathrm{R}}{ }_{\mathrm{ij}} \geq 2$ mast be true (because $\mathrm{D}_{\mathrm{i}} \geq 2$ and $S_{\mathrm{ij}}=1$ mast be true).

\subsection{Effective component reusability}

The effective reusability of the i-th component can thus be expressed in two ways.

The relative reusability $r_{i j}$, which expresses the reusability of the i-th component at the $\mathrm{j}$-th recovery cycle, is defined on the basis of condition $\mathrm{V}_{\mathrm{ij}}^{\mathrm{R}} \geq 2$ as follows:

$$
r_{i j}=\left\{\begin{array}{lll}
0 & \text { if } & V_{i j}^{R}<2 \\
1 & \text { if } & V_{i j}^{R} \geq 2
\end{array}\right.
$$

and therefore assumes a value 1 if the $\mathrm{i}$-th component is reusable at the $\mathrm{j}$-th recovery cycle, otherwise it is equal to 0 .

The absolute reusability $R_{i}$, which expresses the total number of recovery cycles which the i-th component can undergo after its first conventional use, is then given by:

$$
R_{i}=\sum_{j=1}^{m} r_{i j}
$$

where $\mathrm{m}$ is the maximum number of foreseeable recovery cycles for the entire unit, function of $m^{*}$ and of $r_{i j}$ terms. If $R_{i}=0$ the $i$-th component is not reusable, if $R_{i} \geq 1$ the component can be reused a further $R_{i}$ times.

\subsection{Recovery fractions}

The recovery fraction $\Phi_{j}^{\mathrm{P}}$, which expresses the fraction of the total weight of the product reusable at the $\mathrm{j}$-th recovery cycle, is expressed by: 


$$
\Phi_{j}^{P}=\frac{\sum_{i=1}^{n} r_{i j} \cdot P_{i}}{\sum_{i=1}^{n} P_{i}}
$$

These terms define the quantity of material in play in each recovery cycle and therefore already give a quantitative indication of the efficacy and the benefits of the recovery operations. To better characterise these in terms of environmental impact, however, it is appropriate to express them according to the environmental impact associated with the production of each component. This is possible using the environmental indicators available in the literature. Applying specific methodologies, these indicators are used to quantify the impact involved in the production of the more common materials and in standard manufacturing processes (Goedkoop 1995). Indicating the environmental impact of $\mathrm{i}$-th component production by $\alpha_{\mathrm{i}}$, this can be expressed as:

$$
\alpha_{i}=E I_{i}^{m a t} \cdot P_{i}+\sum_{s=1}^{t_{i}} E I_{i}^{p r_{s}} \cdot p_{i}^{p r_{s}}
$$

where

- $\mathrm{EI}_{\mathrm{i}}^{\mathrm{mat}}$ is the unitary eco-indicator for the material making up the i-th component;

- $\mathrm{P}_{\mathrm{i}}$ is the weight of the $\mathrm{i}$-th component;

- $\mathrm{EI}_{\mathrm{i}}^{\mathrm{pr}_{\mathrm{s}}}$ is the eco-indicator which can be associated with the s-th manufacturing process of the i-th component's production cycle, per unit of principle process parameter;

- $\mathrm{p}_{\mathrm{i}}^{\mathrm{pr}_{\mathrm{s}}}$ is the principle process parameter of the s-th manufacturing process of the i-th component's production cycle (e.g. in the case of a cutting process, $\mathrm{p}_{\mathrm{i}}^{\mathrm{pr}_{s}}$ is equal to the length of the cut).

The recovery fraction $\Phi_{j}^{\alpha}$, which expresses the fraction of the product weight reusable at the $j$-th recovery cycle in terms of environmental impact, is expressed by:

$$
\Phi_{j}^{\alpha}=\frac{\sum_{i=1}^{n} r_{i j} \cdot \alpha_{i}}{\sum_{i=1}^{n} \alpha_{i}}
$$


The terms expressed by (8) or (10) define the recovery cycles in that they are functions of the components which take part in each recovery cycle.

\subsection{Extension of useful life}

Useful Life, intended as a period of time for which the entire architecture or part of it is used in the same life cycle, can be considered as an indicator of saving resources. Extending the useful life, in fact, corresponds to a better use of the resources involved in the production phase, and to a safeguard against the excessive dumping of waste.

Already formulated by the authors (Giudice 1999b), on the basis of previous suggestions (Navin-Chandra 1991), this indicator provides a global vision of the product's entire life, beyond the limits of a single life cycle, and is introduced and developed here as a complement to the calculation model proposed in this study.

Summarising some concepts already discussed, therefore, if at the end of its conventional use, of duration $\mathrm{T}$, the product is not recovered in any way, nor reused as a whole, then its useful life is equal to time $\mathrm{T}$ during which it performs the function related to that single use. If, instead, the whole product is reused, or if it is recovered in part, the useful life is extended, since all or parts of the resources employed continue to perform the anticipated function.

Referring to precedent formulation (Giudice 1999b), indicating the number of whole reuses by $\mathrm{nr}$, and the number of recoveries by $\mathrm{m}$, if at the conclusion of each use subsequent to integral reuses, a recovery fraction $\Phi_{\mathrm{j}}$ is recovered and again introduced into the cycle, hypothesising a constant duration of all the uses equal to $\mathrm{T}$, the useful life is then:

$$
U L=\left[1+n r+\sum_{j=1}^{m} \Phi_{1} \cdot \Phi_{2} \cdot \ldots . \Phi_{j}\right] \cdot T
$$

where $\Phi_{\mathrm{j}}$ is the recovery fraction at the $\mathrm{j}$-th recovery cycle. In the real case the number of reusable components coming from the original unit decrease with each successive recovery.

From (11) one obtains the Extension of Useful Life, which quantifies the overall extension of the life of the original components within the same product's life cycle:

$$
E U L=\left[n r+\sum_{j=1}^{m} \Phi_{1} \cdot \Phi_{2} \cdot \ldots . \Phi_{j}\right] \cdot T
$$


From (12) it is simple to define a final indicator which quantifies the extension of useful life after the generic k-th recovery:

$$
E U L_{k}=\left[n r+\sum_{j=1}^{k} \Phi_{1} \cdot \Phi_{2} \cdot \ldots \cdot \Phi_{j}\right] \cdot T
$$

According to the type of investigation required, the recovery fractions expressed by (8) or (10) are introduced into (11), (12) and (13). In the first case it is just necessary to evaluate the weights $\mathrm{P}_{\mathrm{i}}$ of each $\mathrm{i}$-th component. In the second case it is necessary to evaluate the terms $\alpha_{i}$ expressed by (9) (see also 5.3 section).

\section{CASE STUDY: ANALYSIS AND OPTIMISATION OF HEAT EXCHANGER ARCHITECTURES}

The model developed for the analysis and design of recovery cycles was applied to a specific design case: the analysis and optimisation of the architecture of heat exchangers. The specific product seems particularly interesting in relation to the problem in question in that: it is characterised by construction standards developed according to principles of modular architecture which makes the product highly suitable for the recovery of some components at the end of its working life; the experience of the manufacturers has shown wide margins for the application of recovery operations at the end of the product's life.

\subsection{Construction standards of heat exchangers}

The construction of heat exchangers is codified and standardised by clear design guidelines. The definition of the architecture is directed by its subdivision into three main construction modules (two heads and the central body), each of which can be chosen from a range of different design alternatives (TEMA 1988). The various possible combinations in the choice of modules gives rise to a wide variety of architectures. 


\subsection{Operations for recovery at the end of working life}

For some typologies of exchangers, and the uses they are destined for, a non-homogeneous deterioration was found in the metallurgic properties of the steel used. Consequently some longer lasting components would be reusable if they were separable from the constructional unit and if they were considered perfectly efficient from the point of view of their mechanical and thermodynamic properties.

An investigation into the potentiality of the component recovery strategies was conducted with particular regard to two typologies of heat exchanger, with the common parameters of overall volume (shell side capacity 3500 litres, overall length 7-8 m), thermal-pressure working conditions (about $20 \mathrm{bar} / 400^{\circ}$ shell side, about $40 \mathrm{bar} / 300^{\circ}$ tube side) and foreseen use in the industrial plant (shell side fluid VPS-BTMS, tube side fluid R-CRUDE). The two architectures differ in that the first has a detachable shell, coded CFU (Figure 4), while the second is of the floating head type, coded AES (Figure 5). In both cases, after about 6 years use metallographic analysis showed considerable deterioration in the metallurgical properties of the central module shell, good condition of the tubes (potentially reusable after rigorous cleaning) and excellent condition of the remaining components (front and rear end modules). In analogous tests, after a further 6 years use of exchangers regenerated by substituting only the external central module, the reused tubes showed deterioration, while the good condition of the remaining components suggested their suitability for a further and ultimate reuse.

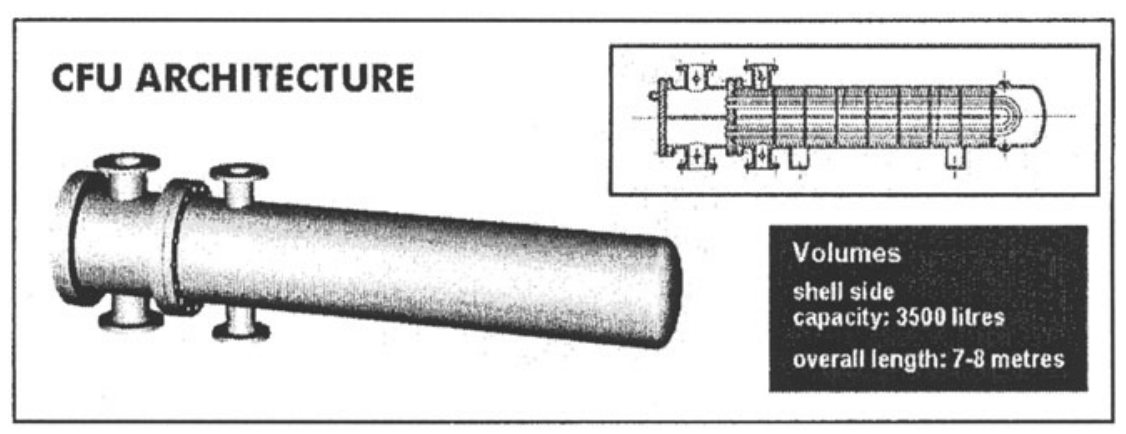

Figure 4. CFU architecture typology 


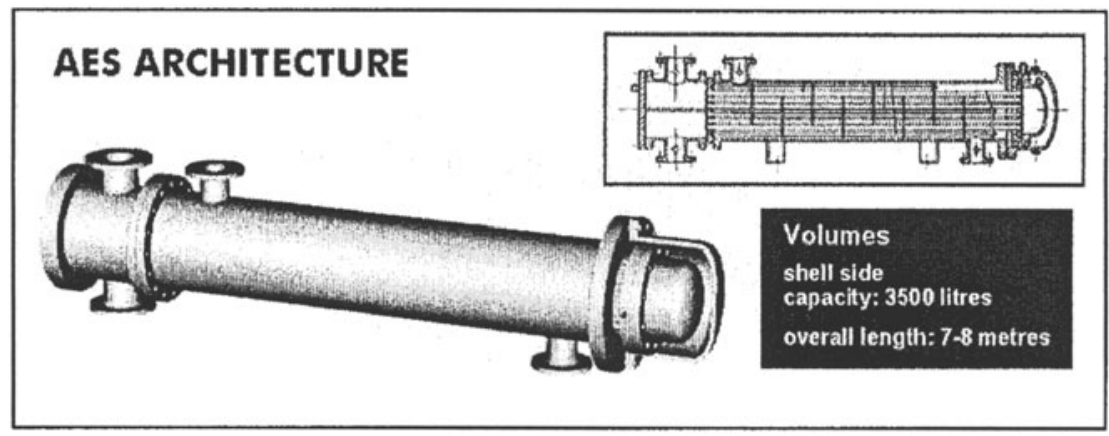

Figure 5. AES architecture typology

The data obtained confirm, therefore, the suitability of applying the recovery cycle analysis developed here in order to evaluate the efficacy of the proposed model in relation to two different design operations:

- comparison between different architecture typologies to evaluate the recovery potential;

- evaluation of design choices aimed at optimising an architecture typology.

\subsection{Application of the calculation model}

The calculation model was applied following the procedure reported in Figure 3.

Analysis of the architectures under examination allowed the identification of the principle components and construction modules. The recovery determining factors were defined making matrices of type (3), and this allowed the definition of two possible recovery cycles and the components or groups of components which can be included on the basis of their properties of durability and separability.

In particular, the predicted duration of each component was that found for the pre-existing components on the basis of the metallographic testing data reported above. The duration of conventional use $\mathrm{T}$ was fixed at 6 years, according to the indications of the same data. Component separability was identified on the basis of a simple analysis of the typologies of jointing between the components, according to the distinction reversible/irreversible.

The recovery fractions were calculated in terms of environmental impact, as in (10), because of their greater significance from the environmental viewpoint. The environmental indicators developed according to the Ecoindicator 95 methodology (Goedkoop 1995) were used in the calculation of 
$\alpha_{i}$ expressed by (9), and for this reason the fractions $\Phi_{j}^{\alpha}$ were tabulated as $\Phi^{\mathrm{EI}}$.

Finally, expressions (12) and (13) were applied for the calculation of indicators of Extension of Useful Life, giving results which will be discussed below.

\subsection{Analysis and evaluation of results}

As above, the applications developed to evaluate the efficacy of the proposed model, followed two different types of design operation: one of comparison and the other of optimisation. In the first case, the aim was to compare the two architecture typologies CFU and AES (some of the data for the two architectures are reported in Table 1 and 2), to evaluate their different recovery potentialities.

Table 1. Data on the CFU architecture

\begin{tabular}{|c|c|c|c|c|c|c|c|}
\hline \multicolumn{8}{|l|}{ CFU ARCHITECTURE } \\
\hline & QUNATTYY & MATERIAL & $\begin{array}{l}\text { WEGGT } \\
\text { [kg] }\end{array}$ & $\begin{array}{c}\text { WEGGHT(TOT) } \\
{[\mathrm{kg}]}\end{array}$ & $\begin{array}{l}\text { EMAT(UNT) } \\
{[\mathrm{mP}]}\end{array}$ & $\begin{array}{l}\text { E MAT } \\
{[\mathrm{mP}]}\end{array}$ & $\begin{array}{c}\text { EI MAT(TOT) } \\
{[\text { [mP] }}\end{array}$ \\
\hline \multicolumn{8}{|c|}{ CENIRAL MODULE + REAR END HEADMODUIE } \\
\hline SHFL & 1 & FB410.1KW & 3953 & 3953 & 4,3 & 16998 & 16998 \\
\hline SHEUL NOEZLE & 2 & ASTMA105/A106 & 44 & 88 & 4,1 & 180 & 361 \\
\hline SHEULCOVER & 1 & FE410.1KW & 341 & 341 & 4,3 & 1466 & 1466 \\
\hline SHEU FLANGE & 1 & ASTMAIOS & 574 & 574 & 4,1 & 2353 & 2353 \\
\hline \multirow[t]{2}{*}{ ** SUPPORT SADDUE } & 2 & FE410.1KW & 101 & 202 & 4,3 & 434 & 869 \\
\hline & & & & 5158 & & & 22047 \\
\hline \multicolumn{8}{|l|}{ FRONT ENDSTATIONARY HEADMODULE } \\
\hline * STATIONARY HEADSHELL & 1 & FE510.1KW & 312 & 312 & 4,3 & 1342 & 1342 \\
\hline * PASS PARTITION & 2 & FE510.1KW & 91 & 182 & 4,3 & 391 & 783 \\
\hline * STATIONARY HEAD NOEZIE & 2 & ASTMA10S/A106 & 44 & 88 & 4,1 & 180 & 361 \\
\hline * STATIONARY TUBESHEET & 1 & ASTMA105 & 2206 & 2206 & 4,3 & 9486 & 9486 \\
\hline \multirow{2}{*}{ ** CHANNEL COVER } & 1 & ASTMA10S & 1697 & 1697 & 4,3 & 7297 & 7297 \\
\hline & & & & 4485 & & & 19268 \\
\hline \multicolumn{8}{|l|}{ TUBES MODULE } \\
\hline${ }^{*}$ TUBES & 1 & FE35.2 & 7327 & 7327 & 4,1 & 30041 & 30041 \\
\hline * LONGTTUDINAL BAFFLE & 2 & FE510.1KW & 760 & 1520 & 4,3 & 3268 & 6536 \\
\hline \multirow{3}{*}{ * TRANSVERSE BAFFLE } & 12 & FE430 & 49 & 588 & 4,3 & 211 & 2528 \\
\hline & & & & 9435 & & & 39105 \\
\hline & & & & 19078 & & & 80420 \\
\hline
\end{tabular}


Table 2. Data on the AES architecture

\begin{tabular}{|c|c|c|c|c|c|c|c|}
\hline \multicolumn{8}{|l|}{ AES ARCHITECTURE } \\
\hline & QUANITY & MATERIAL & $\begin{array}{c}\text { WEGGT } \\
{[\mathrm{kg}]}\end{array}$ & $\begin{array}{c}\text { WEGHT(TOT) } \\
{[\mathrm{kg}]}\end{array}$ & $\begin{array}{l}\text { EI MAT (UNT) } \\
{[\mathrm{mPt}]}\end{array}$ & $\begin{array}{c}\text { EI MAT } \\
{[\mathrm{mPt}]}\end{array}$ & $\begin{array}{c}\text { E MAT (TOT) } \\
{[\mathrm{mPt}]}\end{array}$ \\
\hline \multicolumn{8}{|l|}{ CENTRAL MODULE } \\
\hline SHEL & 1 & FE410.1KW & 3614 & 3614 & 4,3 & 15540 & 15540 \\
\hline SHELL NOZZLE & 2 & ASTM A105 / A106 & 44 & 88 & 4,1 & 180 & 361 \\
\hline SHELL FLANGE REAR HEAD END & 1 & ASTM A105 & 664 & 664 & 4,1 & 2722 & 2722 \\
\hline SHEL L FLANGE STAT HEADEND & 1 & ASTM A105 & 574 & 574 & 4,1 & 2353 & 2353 \\
\hline \multirow[t]{2}{*}{ ** SUPPORT SADDLE } & 2 & FE410.1KW & 101 & 202 & 4,3 & 434 & 869 \\
\hline & & & & 5142 & & & 21845 \\
\hline \multicolumn{8}{|l|}{ REAR END HEAD MODULE } \\
\hline ** SHELLCOVER & 1 & FE410.1KW & 680 & 680 & 4,3 & 2924 & 2924 \\
\hline ** SHEL L COVER FLANGE & 1 & ASTM Al05 & 276 & 276 & 4,1 & 1132 & 1132 \\
\hline ** FLOATING HEADCOVER & 1 & FE510.1 KW & 275 & 275 & 4,3 & 1183 & 1183 \\
\hline ** FLOATING HEAD FLANGE & 1 & ASTM A105 & 387 & 387 & 4,1 & 1587 & 1587 \\
\hline \multirow[t]{2}{*}{ ** BACKING DEVICE } & 1 & ASTM A105 & 403 & 403 & 4,1 & 1652 & 1652 \\
\hline & & & & 2021 & & & 8477 \\
\hline \multicolumn{8}{|l|}{ FRONT END STATIONARY HEAD MODULE } \\
\hline ** STATIONARY HEAD SHELL & 1 & FE510.1KW & 312 & 312 & 4,3 & 1342 & 1342 \\
\hline ** PASS PARTITION & 2 & FE510.1KW & 91 & 182 & 4,3 & 391 & 783 \\
\hline ** STATIONARY HEAD NOZZIE & 2 & ASTMA105/A106 & 44 & 88 & 4,1 & 180 & 361 \\
\hline ** STAT. HEAD FLANGE & 1 & ASTM Al0S & 561 & 561 & 4,1 & 2300 & 2300 \\
\hline ** STAT. HEAD FLANGE COVER SIDE & 1 & ASTM A105 & 528 & 528 & 4,1 & 2165 & 2165 \\
\hline \multirow[t]{2}{*}{ ** CHANNEL COVER } & 1 & ASTM A105 & 1697 & 1697 & 4,3 & 7297 & 7297 \\
\hline & & & & 3368 & & & 14247 \\
\hline \multicolumn{8}{|l|}{ TUBES MODULE } \\
\hline$*$ TUBES & 1 & FE35.2 & 8793 & 8793 & 4,1 & 36051 & 36051 \\
\hline * STATIONARY TUBESHEET & 1 & FES10.1KW & 715 & 715 & 4,3 & 3075 & 3075 \\
\hline * FLOATING TUBESHEET & 1 & FE510.1KW & 515 & 515 & 4,3 & 2215 & 2215 \\
\hline \multirow[t]{3}{*}{ * TRANSVERSE BUFFLE } & 14 & FE430 & 38 & 532 & 4,3 & 163 & 2288 \\
\hline & & & & 10555 & & & 43628 \\
\hline & & & & 21086 & & & 88197 \\
\hline
\end{tabular}

The results of this first type of investigation can be summarised as follows:

- The more complex AES architecture uses more resources and has a greater production impact (overall weight $21086 \mathrm{~kg}$, impact of materials used $88197 \mathrm{mPt}$ ) compared to the CFU architecture (weight $19078 \mathrm{~kg}$, impact $80420 \mathrm{mPt}$ ).

- Durability and separability of the components allow a first recovery cycle of essentially the same modules for both AES and CFU, but permit a second and final recovery cycle only in the case of AES (in Tables 1 and 2 , components with a single asterisk are recovered only in the first cycle, those with two asterisks are also included in the second recovery cycle).

- AES architecture gives greater recovery fractions than CFU, as shown by Graph 1. The fraction of the first recovery cycle $\Phi^{\mathrm{EI}}{ }_{\mathrm{j}}$ is greater than $3.4 \%$, despite the fact that the first recovery covers the same main modules in both cases. This evidences a better distribution of the volumes in AES, with an architecture which is more functional for recovery (because, unlike in CFU, the rear end module is not integrated with the central module). The fraction of the second recovery cycle is distinctly greater $(+163 \%)$, showing a more efficient recovery for AES which, because of its better modularity, allows the second reuse of the entire front end stationary head module. 
- As a direct consequence of the better recovery fractions, the Extension of Useful Life values for AES are greater than those of CFU (Graph 2), slightly greater after the first recovery cycle $(+3.4 \%)$ and substantially so after the second and final recovery cycle $(+19 \%)$.

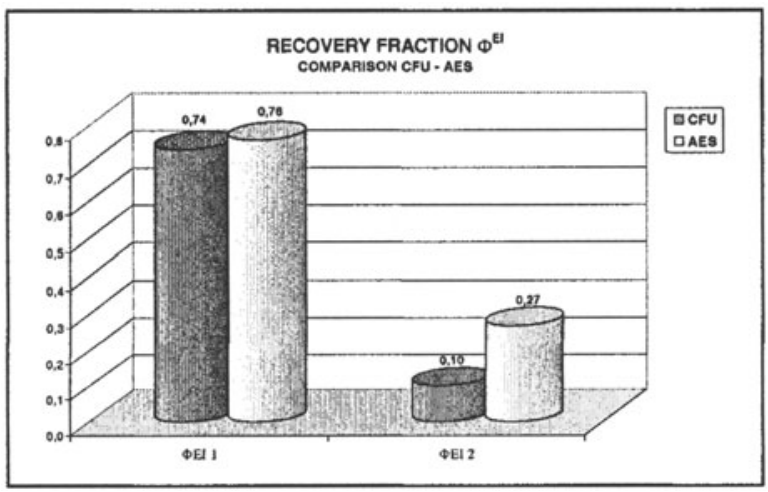

Graph 1. Recovery fraction (CFU-AES)

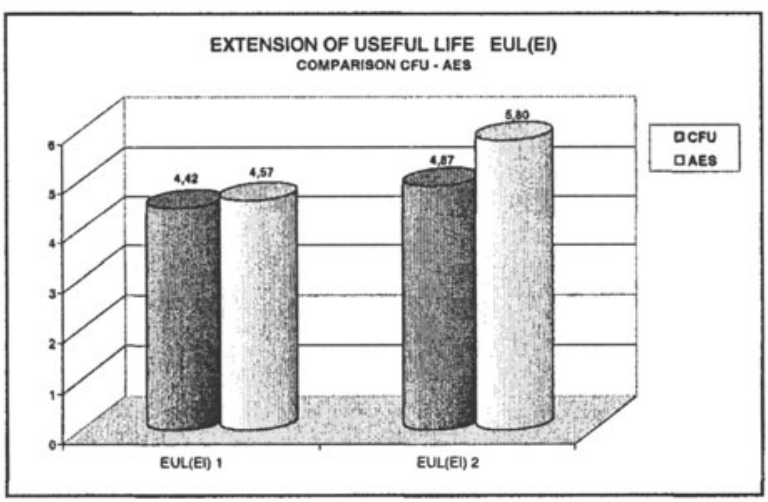

Graph 2. Extension of Useful Life (CFU-AES)

- In conclusion, therefore, the AES construction typology is characterised by a more complex architecture but has better modularity and is more functional for recovery than CFU. This leads on the one hand to the use of more resources and greater production costs, while on the other hand it offers greater suitability for the recovery of these resources.

The second design approach had the aim of evaluating the efficacy of the design tool proposed as an aid to the optimisation of the CFU type architecture. From the comparison with the AES architecture above, it is 
clear that it would be appropriate to make the tube bundle separable from the front end stationary head module, exactly as in AES, with a reversible flanged coupling which connects the central shell, tube plate and the front end shell. The introduction of this modification is therefore proposed as a design choice which is directed at a greater efficiency of the CFU recovery cycles. This results in the optimised architecture CFU* showed in Figure 6, with the principle data reported in Table 3.

The results of the comparison between the two architectures, conventional and optimised, can be summarised as follows:

- CFU* is slightly heavier $(+0.2 \%)$, but also shows a decrease in the overall impact of the materials used $(-0.13 \%)$ due to a different percentage of materials characterised by different environmental impacts (although the differences are minimal).

- Durability and separability of the components allow the first recovery cycle to cover essentially the same construction modules for both CFU and $\mathrm{CFU}^{*}$, but the second and final recovery cycle is possible only for $\mathrm{CFU}^{*}$ (as indicated by the asterisks in Tables 1 and 3 ).

- In the first recovery cycle, CFU* shows a slight decrease in the recovery fraction compared to CFU (-1\%), as reported in Graph 3. Thus halting at the first recovery operation would mean that the optimisation was inefficient. This slight decrease is however fully compensated in the second recovery cycle, made more effective by a better modularity, with a consequent $+92 \%$ increase in the recovery fraction of $\mathrm{CFU}^{*}$ compared to CFU. 


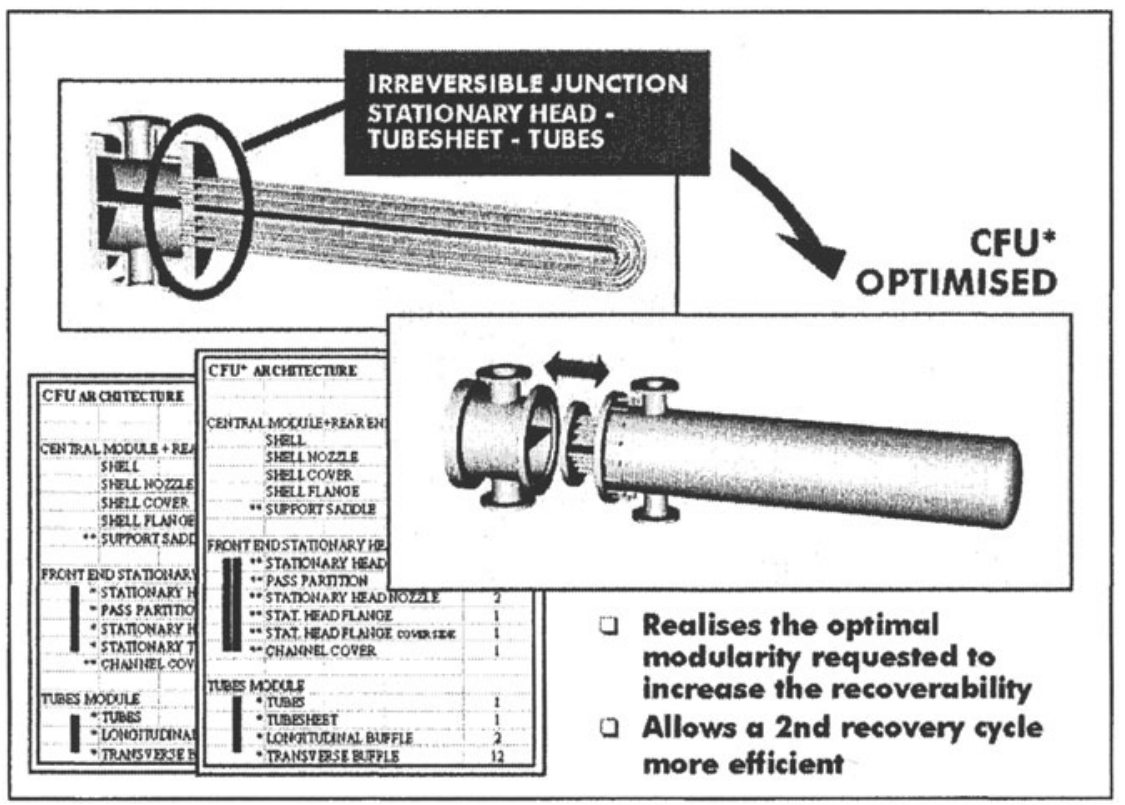

Figure 6. Optimised architecture CFU*

Table 3. Data on the CFU* architecture

\begin{tabular}{|c|c|c|c|c|c|c|c|}
\hline \multicolumn{8}{|l|}{ CFU* ARCHITECTURE } \\
\hline & QUANIITY & MATERIAL & $\begin{array}{c}\text { WEGGHT } \\
{[\mathrm{kg}]}\end{array}$ & $\begin{array}{c}\text { WEIGHT (TOT) } \\
{[\mathrm{kg}]}\end{array}$ & $\begin{array}{c}\text { EI MAT (UNIT) } \\
\text { [mPt] }\end{array}$ & $\begin{array}{l}\text { E MAT } \\
\text { [mPt] }\end{array}$ & $\begin{array}{c}\text { EI MAT (TOT) } \\
\text { [mPt] }\end{array}$ \\
\hline \multicolumn{8}{|l|}{ CENTRAL MODULE+REAR END HEAD MODULE } \\
\hline SHEUL & 1 & FE410.1KW & 3953 & 3953 & 4,3 & 16998 & 16998 \\
\hline SHEL NOZZZE & 2 & ASTM A105 / A106 & 44 & 88 & 4,1 & 180 & 361 \\
\hline SHELLCOVER & 1 & FE410.1KW & 341 & 341 & 4,3 & 1466 & 1466 \\
\hline SHEU LLANGE & 1 & ASTM A105 & 718 & 718 & 4,1 & 2942 & 2942 \\
\hline \multirow[t]{2}{*}{ ** SUPPORT SADDIE } & 2 & FE410.1KW & 101 & 202 & 4,3 & 434 & 869 \\
\hline & & & & 5302 & & & 22635 \\
\hline \multicolumn{8}{|l|}{ FRONT END STATIONARY HEAD MODULE } \\
\hline ** STATIONARY HEAD SHELL & 1 & FE510.1KW & 312 & 312 & 4,3 & 1342 & 1342 \\
\hline ** PASS PARTITION & 2 & FE510.1KW & 91 & 182 & 4,3 & 391 & 783 \\
\hline ** STATIONARY HEAD NOZZLE & 2 & ASTM A105/A106 & 44 & 88 & 4,1 & 180 & 361 \\
\hline ** STAT. HEAD FLANGE & 1 & ASTM A105 & 701 & 701 & 4,1 & 2875 & 2875 \\
\hline ** STAT. HEAD FLANGE COVER SIDI & 1 & ASTM A105 & 528 & 528 & 4,1 & 2165 & 2165 \\
\hline \multirow[t]{2}{*}{ ** CHANNEL COVER } & 1 & ASTM A105 & 1697 & 1697 & 4,3 & 7297 & 7297 \\
\hline & & & & 3508 & & & 14822 \\
\hline \multicolumn{8}{|l|}{ TUBES MODULE } \\
\hline * TUBES & 1 & FE35.2 & 7327 & 7327 & 4,1 & 30041 & 30041 \\
\hline * TUBESHEET & 1 & FE510.1KW & 873 & 873 & 4,3 & 3752 & 3752 \\
\hline * LONGITUDINAL BUFFLE & 2 & FE510.1KW & 760 & 1520 & 4,3 & 3268 & 6536 \\
\hline \multirow[t]{3}{*}{ * TRANSVERSE BUFFLE } & 12 & FE430 & 49 & 588 & 4,3 & 211 & 2528 \\
\hline & & & & 10308 & & & 42857 \\
\hline & & & & 19117 & & & 80314 \\
\hline
\end{tabular}

- The results regarding the Extension of Useful Life (reported in Graph 4) mirror those of the recovery fractions, therefore again the comparison between $\mathrm{CFU}^{*}$ and CFU shows a slight fall in EUL after the first recovery cycle (-1\%) and a substantial increase after the second and final 
recovery $(+7.4 \%)$. This underlines the importance of using an indicator which extends the evaluation over all the recovery cycles for a complete analysis of the efficiency of the recovery operation.

- In conclusion, the optimisation proposed for the CFU architecture is appreciable only with an evaluation of the entire potentiality of recovery.

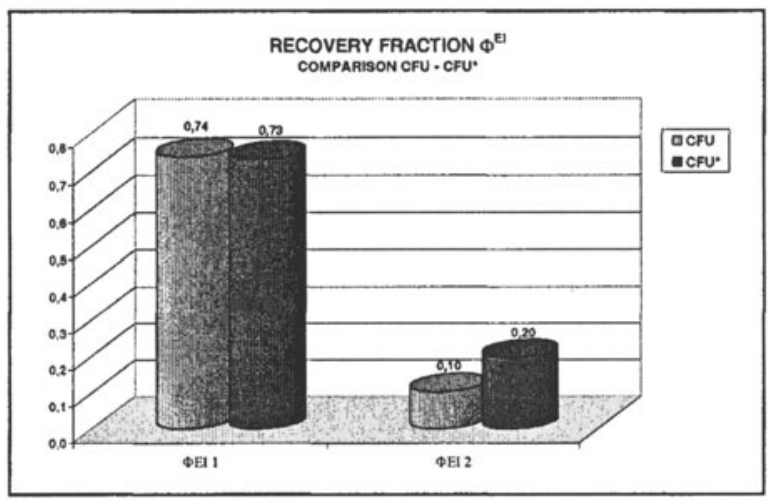

Graph 3. Recovery fraction (CFU-CFU*)

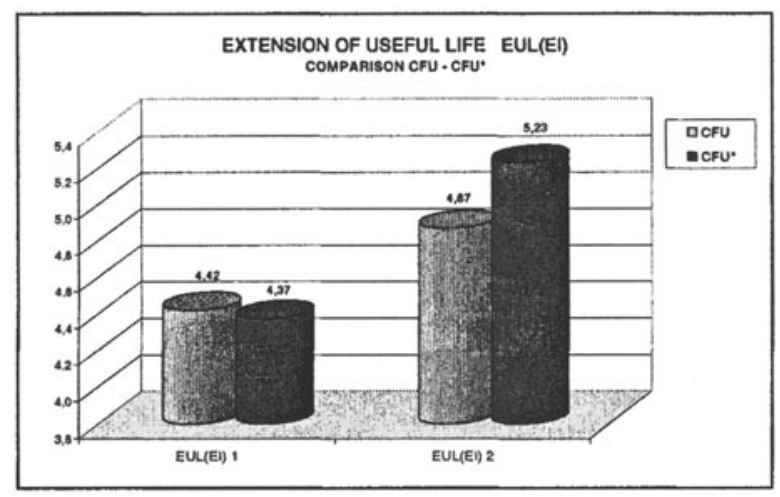

Graph 4. Extension of Useful Life (CFU-CFU*)

Finally, Graphs 5 and 6 show, respectively, the greater efficiency of the AES architecture compared to the other two examined, in terms of the increases of EUL after the first and second recovery, and the trend of the UL over successive recovery cycles for the three architectures. 


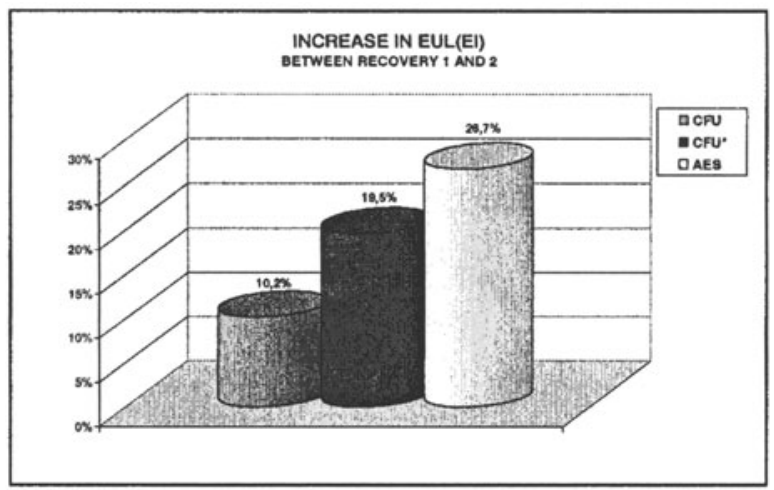

Graph 5. Increase in EUL between 1st and 2nd recovery

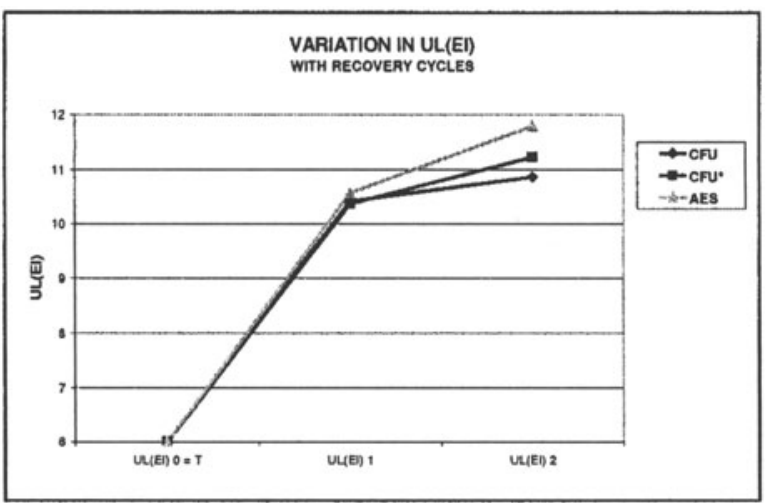

Graph 6. Trend of UL over successive recovery cycles

\section{CONCLUSIONS}

The study proposes a tool to evaluate design choices directed at the most efficient planning of the recovery cycles for a product at the end of its working life. The methodology developed and the calculation model which sustains it, are based on the evaluation of the determining factors which define the potentiality of each component of a constructional unit according to the possibilities of its recovery and reuse, with the aim of quantifying the benefits of the recovery of resources in terms of the extension of the product's useful life.

Applied as an instrument of analysis and optimisation of the suitability for recovery of the modules characterising the architecture of heat 
exchangers, the calculation model proposed here seems to confirm the potential for recovery as an aid to the design of recovery cycles, and to suggest its integration with other tools developed for design orientated towards the environmental quality of products.

\section{REFERENCES}

Billatos, S., Basaly, N. (1997). Green Technology and Design for the Environment, Taylor \& Francis, Bristol PA.

Burke, D., Beiter, K., Ishii, K. (1992). Life-Cycle Design for Recyclability, In ASME Design Theory and Methodology Conference, Scottsdale.

Dowie, T., Simon, M. (1995). Guidelines for Designing for Disassembly and Recycling, In $R$ '95 Conference "Recovery, Recycling, Re-integration", Geneva.

Giudice, F., La Rosa, G., Risitano, A. (1999). Models and Indicators for the Cost-Benefit Analysis of a Green Product, In EcoDesign'99 $1^{\text {st }}$ International Symposium on Environmentally Conscious Design and Inverse Manufacturing, Tokyo.

Giudice, F., La Rosa, G., Risitano, A. (1999). Indicators for Environmentally Conscious Product Design, In EcoDesign'99 $1^{\text {st }}$ International Symposium on Environmentally Conscious Design and Inverse Manufacturing, Tokyo.

Goedkoop, M., Demmers, M., Collignon, M. (1995). The Eco-indicator 95: Manual for Designers, Pré Consultants BV, Amersfoort, The Netherlands.

Graedel, T., Allenby, B. (1998). Design for Environment, Prentice Hall, Upper Saddle River NJ.

Huang, C. (1996). Design for X: Concurrent Engineering Imperatives, Chapman \& Hall, London.

Ishii, K. (1995). Life-Cycle Engineering Design, ASME Journal of Mechanical Design, vol. 177.

Ishii, K. (1999). Incorporating End-of-Life Strategy in Product Definition, In EcoDesign '99 $1^{\text {st }}$ International Symposium on Environmentally Conscious Design and Inverse Manufacturing, Tokyo.

Johnson, M., Wang, M. (1998). Economical Evaluation of Disassembly Operations for Recycling, Remanufacturing and Reuse, International Journal of Production Research, vol. 36 , no. 12 .

Kusiak, A. (1992). Concurrent Engineering: Theory and Practice, Wiley \& Sons, New York.

Lambert, A. (1997). Optimal Disassembly of Complex Products, International Journal of Production Research, vol. 35, no. 9.

Navin-Chandra, D. (1991). Design for Environmentability, In ASME Design Theory and Methodology Conference, Miami.

Navin-Chandra, D. (1994). The Recovery Problem in Product Design, Journal of Engineering Design, vol. 5, no.1.

Tang, Y., Zhou, M. C., Zussman, E., Caudill, R. J. (2000). Disassembly Modelling, Planning, and Application: A Review, In 2000 IEEE International Conference on Robotics and Automation, San Francisco, CA.

TEMA (1988). Standards of the Tubular Exchanger Manufacturers Association, Tubular Exchanger Manufacturers Association, New York. 